\title{
The relationship between technology and functionality of rural water points: evidence from Tanzania
}

\author{
A. Jiménez and A. Pérez-Foguet
}

\begin{abstract}
This paper presents an analysis of the relationships between technology of water point, management related practices and functionality over time through an extensive water point mapping study made in 15 rural districts of Tanzania, which covered $15 \%$ of the total rural population of the country. Results show irregular functionality rates at district level by technology, but reveal statistical dependence between functionality and technology at regional level. Management-related questions show that reported expenditure is the indicator most related to functionality. All categories of water points show very low performance over time. In the first five years of operation, about $30 \%$ of water points become non-functional. Only between $35 \%$ and $47 \%$ of water points are working 15 years after installation, depending on the technology. By categories, hand pumps are the less durable of the technologies studied. We suggest that more emphasis has to be placed on the creation of community capacities to manage the services during and after the installation of water points. At the same time, the role of decentralised government has to be strengthened to provide support to community services in the long term. Key words | access, Africa, rural areas, sustainability, Tanzania, technology, water supply
\end{abstract}

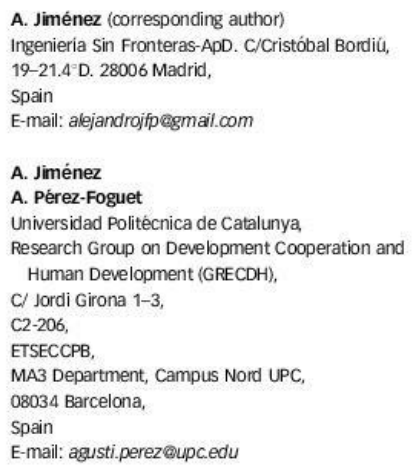

\section{INTRODUCTION}

Sustainability of rural water supply programmes in developing countries is a key concern for the sector. Current estimations for Sub-Saharan Africa are that only two out of three water points in rural areas on the continent are functional at any given time (RWSN 2009), recognising at the same time the absence of wide data sets to backup this estimation. Other sources estimate a functionality of 40 to $50 \%$ for hand pumps in Africa (Harvey \& Reed 2004). In general, the paucity of consistent water-sector related data is a key constraint for effective progress (Biswas \& Seetharam 2008). This is a general challenge in the region, as demonstrated by the status of development of Sector Management Information Systems in the Sub-Saharan region (WSP 2007).

The case of Tanzania reflects the general challenges. Between 30\% (GoT 2002) and 46\% (Wateraid 2009) of the water points are estimated to be not functional. Data published by the ministry, which are based on the coverage reported by districts, are not always reliable. District water engineers recognise that data are not based on an extensive review of the situation. Inter-annual variability is also very high. For instance, from 2007 to 2008, 30 districts reported a coverage variation of at least $10 \%$ on the previous year. Of these, 16 reported a variation of over $20 \%$, and seven reported one of over 30\% (GoT 2008).

Water Point Mapping (WPM) approach has been specifically designed as a procedure to provide reliable information about the status of water services in the rural areas. It has been applied extensively by Water Aid and other NGDO in some African countries for a number of years. Water point mapping (WPM) can be defined as an "exercise whereby the geographical positions of all improved water points in an area are gathered in addition to management, technical and demographical information. This information is collected using GPS and a questionnaire located at each water point. The data is entered into a geographical information system and then correlated with available demographic, 
administrative, and physical data. The information is displayed using digital maps" (Wateraid, ODI 2005). The main function of WPM is to simply and objectively demonstrate how water points are distributed within a territory; thus, it helps to define reliable access indicators constructed from the lowest geographical level using the available demographic data (Jiménez \& Pérez-Foguet 2008) and it serves as a valuable analysis and planning tool for government, both at decentralised (Jiménez \& Pérez-Foguet 20roa) and national level.

The aim of the study is to establish the relationships between technology, functionality and durability of rural water points, based on the review of WPM data from 5,921 improved water points. Data were collected between 2005 and 2006 by Wateraid.

The structure of the paper is the following. First, the methodology used for the analysis is explained. Afterwards, the results are discussed making three distinctions: i) the relationship between functionality and category of water point; ii) the relationship between functionality and management related information; iii) the functionality of water points over time. The Discussion points out some reasons for the results obtained. The Conclusions give some recommendations and suggest further research.

\section{METHODS}

\section{Water point mapping}

As has been said, WPM surveys all improved water points in a certain area (a district, in this case). The definition of improved water point is consistent with that internationally accepted (WHO/UNICEF 200o). The surveys are done with the collaboration of local authorities down to village level. All villages are visited, even if official data do not register any improved water point there. The participation of local authorities at various levels reduces the risk of leaving certain parts of the villages without surveying.
The information is collected through a questionnaire for each improved water point. This contains essentially the following:

- General information about each water point: location, position, name, type of water point, condition (functional, not functional, stolen, under repair), year of construction, funding agency and installer.

- Management information: institution in charge of the management, seasonality of service, operation and maintenance $(\mathrm{O} \& \mathrm{M})$ practices (if meetings related to these aspects were celebrated, and whether income and expenditure were collected in the previous year to the survey).

- Users, perception about the quality and quantity of the service.

One water point (WP) is considered to be functional if it yields water regularly and is being used by people as a water source on a day to day basis. A WP is non-functional if it does not yield water for any reason, whether due to a hardware problem, to the source being dry, or to poor management. In our analysis, non-functional water points also include those that are under construction and/or were stolen.

Different WPM campaigns sponsored by different stakeholders include variations in the questions included. In recent years we observe a tendency to reduce the number of questions to those that could be answered with precision at local level and/or that can be analysed when aggregated. In our analysis, this same principle is observed, as explained hereinafter.

\section{Category of water points}

Type of water point is recorded in WPM including detailed description of technological elements and source (Figure 1). Table 1 describes the four main categories used in this work to aggregate water points (WP). The three main categories are the same as those used by the Ministry of Water to allocate funds for recurrent costs at the district level (GoT 2006). As a

\begin{tabular}{|c|c|c|c|}
\hline \multirow[b]{2}{*}{ 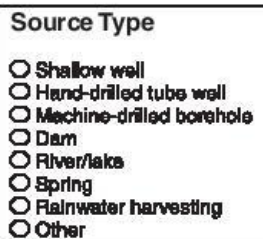 } & \multicolumn{2}{|c|}{ Extraction System } & Water Point Type \\
\hline & $\begin{array}{l}\text { ONoni } \\
\text { OMono } \\
\text { Ocemo } \\
\text { Ocimax } \\
\text { OKsB } \\
\text { O Submersible } \\
\text { OGrantly }\end{array}$ & 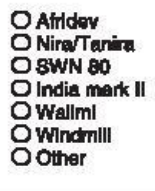 & $\begin{array}{l}\text { O Hand pump } \\
\text { O Comunal standpipe } \\
\text { O Comumal atandpipe multiple } \\
\text { O Cartls trough } \\
\text { O Dam } \\
\text { O Improved spring } \\
\text { O Windmll } \\
\text { O Other }\end{array}$ \\
\hline
\end{tabular}

Figure 1 | Information related to water point category recorded in Water Point Mapping campaigns. 
Table 1 | Water points analysed grouped by category

\begin{tabular}{|c|c|c|c|}
\hline Category & Definition & $\begin{array}{l}\text { Central regions } \\
\text { Number of WP }\end{array}$ & $\%$ of sample \\
\hline All handpumps & $\begin{array}{l}\text { All water points providing water through a handpump, regardless of its } \\
\text { brand and the type of well/borehole. }\end{array}$ & 2,326 & $39.3 \%$ \\
\hline Motorised pumping systems & $\begin{array}{l}\text { All water points fed by a pumping device operated through any kind of } \\
\text { non-manual extraction system, excluding windmills. }\end{array}$ & 2,180 & $36.8 \%$ \\
\hline Gravity Fed & All water points fed by gravity systems, regardless of the type of source. & 1,263 & $21.3 \%$ \\
\hline Others & $\begin{array}{l}\text { Protected springs and rainwater-harvesting not feeding networks; water } \\
\text { points fed by windmills. }\end{array}$ & 152 & $2.6 \%$ \\
\hline
\end{tabular}

result of that, these three categories are the ones used officially for the analysis of water situation at the district level. Others include a quite heterogeneous number of water points. They were not further split as all together they represent only $2.6 \%$ of the water points mapped. The sample is still too small to make conclusions on this category.

These categories help to group in a meaningful and understandable way all the possible combinations of water types, type of sources and extraction systems, facilitating the analysis of data. Apart from the abovementioned, there were 511 cattle troughs mapped, and 382 points could not be put in any category because of contradictions or absence of answers in the questionnaires. It is important to notice that only 49 of them were functional water points. Hence, the sample that was used is of 5,921 water points. From those, 5,852 contain the information of the year of construction. These are used for the analysis of functionality over time.

\section{Methodology for the analysis}

The functionality of each technological category of water point was established by dividing the number of functional WP by the corresponding total number of WP. The values are analysed at different geographical levels, using corresponding variables to segment the data set.

The results of the management-related questions are analysed in comparison to category of WP and functionality, also at different geographical levels.

Pearson's chi-square test was used to assess if a couple of the characteristics of the water points can be considered independent or not. The two-sided exact significance of the test was computed. Values greater than 0.10 are associated to independence of both variables, i.e. the differences observed are probably due to chance, and values lower than 0.05 are associated with a real relationship between both. Crosstabulation is layered using geographical variables. The statistical computations were done using the SPSS v15.0 software.

Afterwards, the relationship between functionality rates, years after construction and category is defined. The decay of functionality over time for each category is estimated by disaggregating water points (WP) in five year-groups, and computing the average functionality for each group. WP constructed before 1974 were grouped together. Descending functionality-time functions were represented by category of water point (Figure 4).

\section{RESULTS}

This section provides the results for the 15 districts studied. First, the functionality by category of WP is assessed in every district. Afterwards the relationship between the functionality of WP and the management related questions included in the study is described. Finally the relationship between the functionality and the years passed after construction of the WP is analysed.

\section{Functionality by category of water point}

Functionality by category does not vary greatly among categories. The functionality rates were $45.31 \%$ for hand pumps, $48.61 \%$ for gravity-fed systems, $44.36 \%$ for motorised systems, and $36.18 \%$ for other systems. In aggregated terms we obtain a functionality of $45.4 \%$. Results show a very different functionality rate by category of water point in each of the districts studied, as shown in Table 2 (districts are named by numbers 
Table 2 | Rate of functionality by category of water point and district

\begin{tabular}{|c|c|c|c|c|c|c|c|c|c|c|c|c|c|c|c|}
\hline \multirow[b]{2}{*}{ Category of WP } & \multicolumn{15}{|c|}{ Districts } \\
\hline & 1 & 2 & 3 & 4 & 5 & 6 & 7 & 8 & 9 & 10 & 11 & 12 & 13 & 14 & 15 \\
\hline All technologies & $79 \%$ & $76 \%$ & $67 \%$ & $53 \%$ & $40 \%$ & $58 \%$ & $37 \%$ & $43 \%$ & $16 \%$ & $29 \%$ & $9 \%$ & $86 \%$ & $37 \%$ & $43 \%$ & $34 \%$ \\
\hline Handpumps & $80 \%$ & $69 \%$ & $49 \%$ & $42 \%$ & $47 \%$ & $61 \%$ & $67 \%$ & $51 \%$ & $19 \%$ & $13 \%$ & $11 \%$ & $86 \%$ & $38 \%$ & $59 \%$ & $46 \%$ \\
\hline Gravity-fed & $82 \%$ & $\underline{76 \%}$ & $71 \%$ & $65 \%$ & $31 \%$ & $35 \%$ & $22 \%$ & $23 \%$ & $6 \%$ & $36 \%$ & $27 \%$ & $0 \%$ & $42 \%$ & $41 \%$ & $88 \%$ \\
\hline Motorised & $77 \%$ & $79 \%$ & $\underline{76 \%}$ & $58 \%$ & $56 \%$ & $66 \%$ & $4 \%$ & $36 \%$ & $14 \%$ & $40 \%$ & $3 \%$ & $100 \%$ & $34 \%$ & $17 \%$ & $22 \%$ \\
\hline Others & $50 \%$ & $100 \%$ & $20 \%$ & $56 \%$ & $0 \%$ & - & - & - & - & $0 \%$ & $0 \%$ & $100 \%$ & $43 \%$ & $11 \%$ & $41 \%$ \\
\hline
\end{tabular}

Note: Underlined values correspond to the predominant category in each district.

in the graphic). Values for Others category have to be taken with caution, due to the low number of points that fall into this category when analysed per district.

Given this fact, the statistical dependence relationships between functionality and technology category of WPs were determined at different spatial scales. A clear relationship (significance equal to 0.01) was found with grouped data, as well as with data disaggregated by region (zero significance in all three regions). When information was disaggregated by district, nine out of 15 were found to have a statistical relationship with a significance level of less than 0.05 . Hence, it can be concluded that the functionality and category of WPs can be considered statistically dependent at the supra-regional and regional scales and, to a lesser extent, at the district scale.

\section{Relationship between functionality of WP and management related questions}

The analysis of the questions dealing with management at the community level did not yield conclusive results. Positive management practices were not exclusive of functional WPs, and, conversely, negative ones were not exclusive of non-functional WPs, as one might expect a priori. Table 3

Table 3 | Answers to management related questions of functional and non-functional water points for the 15 districts studied, regardless of category of WP

\begin{tabular}{clll} 
& $\begin{array}{l}\text { Held meetings } \\
\text { last year }\end{array}$ & $\begin{array}{l}\text { Had income } \\
\text { last year }\end{array}$ & $\begin{array}{l}\text { Had expenditure } \\
\text { last year }\end{array}$ \\
\hline $\begin{array}{c}\% \text { of Functional } \\
\text { WP that }\end{array}$ & $79.3 \%$ & $54.5 \%$ & $35.3 \%$ \\
$\begin{array}{l}\text { \% of Not Functional } \\
\text { WP that }\end{array}$ & $68.7 \%$ & $43.3 \%$ & $17.1 \%$ \\
\hline
\end{tabular}

shows that meetings were held at a quite similar rate regardless of functionality. Income was reported to be slightly above $50 \%$ for functional WPs but 43\% for non-functional ones. Only $35.3 \%$ of functional WPs and $17.1 \%$ of not functional WPs reported expenditures for the year prior to the survey.

Fewer than $10 \%$ of respondents overall said they did not know whether there had been expenditures. Fewer than 3\% declared that the system had expenditures but no income, which could be interpreted as meaning that there is no contradiction between the answers. Finally, $62 \%$ of the functional WPs that reported income also had expenditures, which seems reasonable for a functional service.

Questions were further disaggregated by category (Figures 2 and 3). Functional motorised systems had the highest rates of income and expenditure $(66 \%$ and $54 \%$, respectively). Gravity-fed systems had low scores in both income (44\%) and expenditure (35\%). Functional hand pumps reported expenditures in only $19 \%$ of the cases. The results for non-functional WPs (Figure 4) show less management practices. Meetings took place at a similar rate regardless of the category of WP. Income was collected in $43 \%$ of the cases for not functional WP. Unfortunately, the data do not tell us whether this money was to be used for reconstruction, as an initial contribution for another WP, or for other purposes. Expenditures were lower in all categories when WPs were non-functional, and the difference is especially big for motorised systems. It is remarkable that expenditure is significantly lower for handpumps than for other categories in both the functioning and non-functioning status. As has been already explained, the data are based on self-reporting of communities through the water point mapping surveys.

Management-related questions and functionality were statistically dependent at the supra-regional and regional scales, without considering data disaggregated by technology category, but not at the district scale. When disaggregated by 


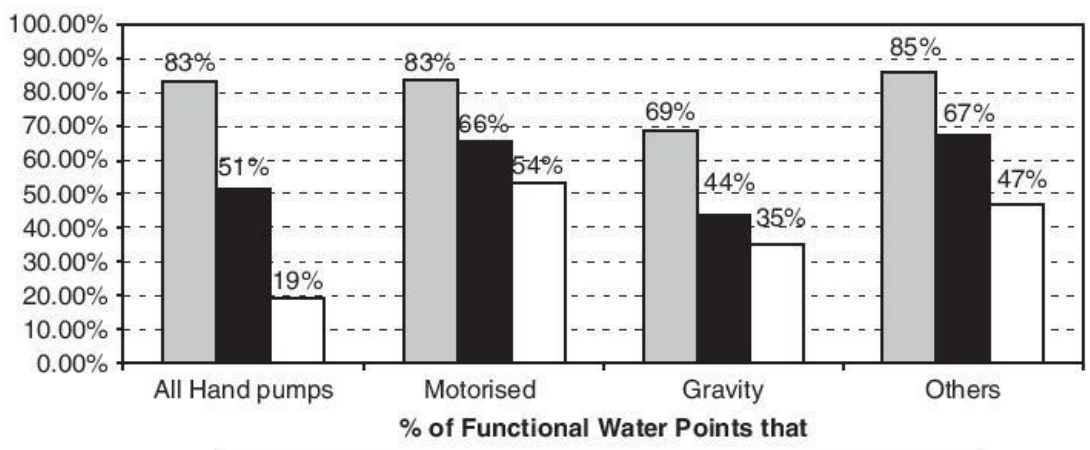

$\square$ Held Meetings held last year $\mathbf{m}$ Had Income last year $\mathbf{\square}$ Had Expenditure last year

Figure 2 Answers to management related questions for functional water points, grouped by category of water points.

district, only one-third of the districts showed a dependence relationship between functionality and meetings and functionality and income. Expenditure showed a slightly higher dependence, with a significance of less than 0.05 in eight out of 15 districts.

Analyses carried out with data disaggregated by technology category showed that most combinations give dependence associations at the supra-regional level (all but the "other" category and the question about meetings), but significances of less than 0.05 are found in just one-third of the combinations, when analysis is downscaled at the regional level. Thus, if disaggregated technology categories are considered (Figures 3 and 4), the relationship between functionality and management questions should be established at the supra-regional scale.

Analyses also confirmed that expenditure is the most suitable question for ascertaining how management affects functionality, and, in all three regions, the functionality of the motorised WPs was found to be related to the reported expenditure.

\section{Functionality by category over time}

The following methodology was used to analyse the relationship between category and time after installation of the WPs. The WPs were grouped by five-year periods after construction regardless of location. Figure 1 shows the average functionality for each group and a trend curve for each category. Hand pumps and motorised WPs have very regular descending functionality-time curves, with $\mathrm{R}^{2}$ values of 0.99 and 0.98 , respectively. Gravity-fed WPs show a more irregular trend: the functionality of those built in the early 1990s was very low (43\%), while those built between 1985 and 1990 were performing better (with a functionality of 50\%), and those built between 1980 and 1985 remained functional in below $20 \%$ of the cases. As a result, the trend curve $\left(\mathrm{R}^{2}=0.77\right)$ for gravity-fed WPs starts with an initial low functionality rate but it has a flatter slope than the others. For the "other" category, the oldest WPs (more than 25 years old) were functional in $24 \%$ of cases, whereas those built in the past five years had a functionality rate of $86 \%$. The trend

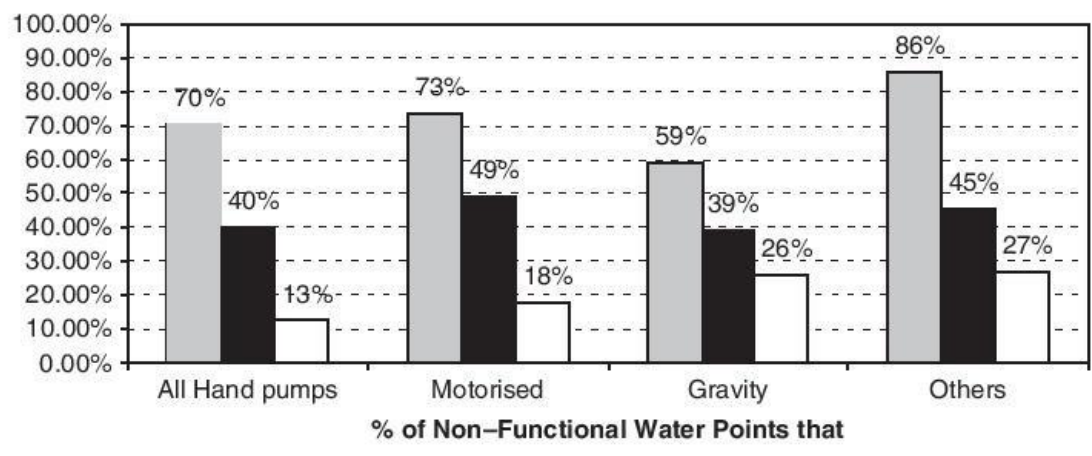

$\square$ Held Meetings held last year $\mathbf{H a d}$ Income last year $\mathbf{a}$ Had Expenditure last year

Figure 3 | Answers to management related questions for non-functional water points, grouped by category of water points. 


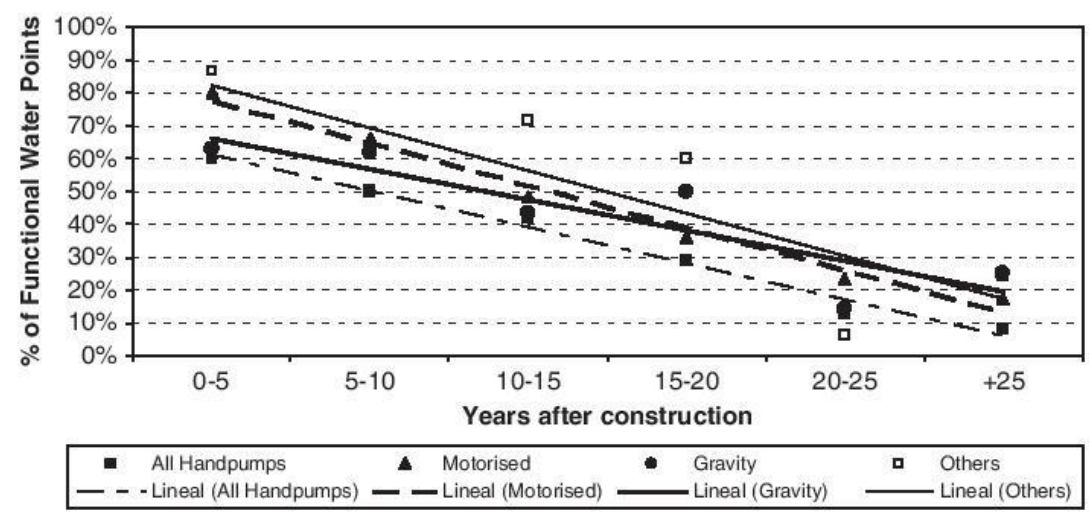

Figure $\mathbf{4} \mid$ Rate of functionality by category of water point over time.

curve $\left(R^{2}=0.68\right)$ shows a good performance of this category of WP over time, though the size of the sample in this category is small to extract conclusions (Table 1).

Simple linear regressions by category yielded interesting results. Hand pumps had the least favourable functionalitytime function, dropping from $61 \%$ in the first five years to $6 \%$ in the 25 -year period. Motorised systems started at $77 \%$ and dropped to $13 \%$ in the same period. Gravity-fed systems worked better in the long run than any other category of WP, dropping from $66 \%$ to $20 \%$. In all three categories, just 35 to $47 \%$ of WPs were working 15 years after installation. WPs in the "other" category had better scores, but this category included very few WPs (just 152 out of 6,814) and, as explained above, grouped WPs of very different types.

\section{DISCUSSION}

\section{Functionality by category of water point}

The very different rates of functionality found for the same technology in neighbouring districts confirm that many factors other than technology affect sustainability. For the case of Tanzania, the literature points out the limitations of community management of funds (World Bank 2008), the difficult relationship between water user entities and elected village representatives (Cleaver \& Toner 2006), the low professionalism in the management of services (Giné \& Pérez-Foguet 2008), and the ability to meet operation and maintenance costs (Harvey 2007).

Since the governance structure is the same for all regions, we analysed the relationship with general poverty indicators. We checked the functionality of water points against the proportion of people below the poverty line, and the propor- tion of adult literate people. We did not find any statistical relationship either at district or at regional level. Hence, we attribute the variability of functionality by region to the differences in the political stability and the social cohesion of the communities. The absence of local conflicts, both social and political, and the degree of ownership of the services among their members have great impact on the durability of the services.

\section{Functionality versus management related questions}

The three questions analysed show different degrees of usefulness. The results show that the celebration of meetings does not have any relationship with the functionality of the water points concerned.

As regards income and expenditure, both have a more direct relationship with the functionality of the water point. The statistical analysis pointed out that expenditure is the indicator more related to functionality of water points. In aggregated terms, only $35.3 \%$ of functional WPs reported expenditures for the year prior to the survey, which indicates poor preventive maintenance of the systems. This percentage comes down to $17.1 \%$ for non-functional water points. Regular payment is a good indicator for sound management. Collection of funds ad-hoc when the system breaks down has significant risks. When a technical problem arises, the money needed to repair it is frequently above what can be collected in a short period of time in the community. Also, income is quite seasonal in many rural areas. When analysed by category of water point, the results of management questions are coherent with the functionality-time functions obtained: functional hand pumps declare making expenditure in only $19 \%$ of the cases, while motorised in $54 \%$ of them. 


\section{Functionality of water points over time}

In general terms, more than $30 \%$ of water points become not functional in the first five years of operation. After this period, the functionality decreased at a slower rate (another 30\% of WP became non-functional in the following 15 years), which points out the crucial importance of the first period after construction for the success of the service.

We highlight that hand pumps show the least favourable functionality-time behaviour of all categories. Management requirements are lower than in any other category, but handpumps are usually installed for a reduced number of users in fairly isolated places. Lack of spare parts and local technical capacities is a challenge. Moreover, the focus on installing a simple technology might have led to the scant attention paid by the programs to building organisational capacities at community level, which remain critical when a maintenance problem arises (either to collect funds, to buy the spare parts or to contract a technician).

Gravity systems show an irregular trend between periods but the best performance in the long run. We presume that the ease of the technology and low operational costs of this category of water point are determinant for the durability over time. The management related questions do not reveal specially good performance in this category. It is remarkable that the WPs of this category constructed between 1985 and 1990 show the best performance over time. This corresponds to the second half of the International Decade for Water and Sanitation, which targeted full coverage of services for 1990. During the early 1980 s many international donors had been supporting detailed plans and capacity building for increasing rural access at regional level (Therkildsen I988). The 19851990 period saw the implementation of part of those plans with technical support from donors. From 1991, the failure of the targets of the Decade reduced the support given by international actors. At the same time, the new water policy shifted more responsibilities to end users (GoT I99I), while the systems were still centrally designed and implemented, which did not enhance ownership and willingness to pay from the end users (Jiménez \& Pérez-Foguet 20Iob). This transition period from a supply led approach to a community owned approach showed unusually low performance in this category (Figure 4).

It is also significant that motorised pumping systems have a very good performance in the first period, and maintain a similar descending slope as the others in the long term. We presume that the high degree of community organisation which is needed to manage the service from the starting point (either to give direct service provision or to manage its subcontracting) balances the technical challenges for O\&M.

\section{CONCLUSIONS}

This study showed how water point mapping data can be used to increase the knowledge about the various factors affecting durability of rural water points. The results show that hand pumps are the less durable of the categories over time, while motorised services perform better. This shows how the investment to create community social capital for management is as important as the technology itself for the sake of sustainability; unfortunately, this aspect seems to be overlooked when it comes to implementation of programs.

In any case, the general functionality of water points over time is very low. Service delivery management approach has to be reviewed; neither the centralised supply led approach used in the country until the $1990 \mathrm{~s}$, nor the community full management model used thereafter, seem to obtain good results in the long term. The role of decentralised government is crucial and needs to be strengthened to improve their support and regulation role and increase sustainability in the long term. At the same time, alternative management systems, including the participation of local private sector, have to be promoted in the rural areas, in order to provide communities with choices for managing the services.

The analysis of the management related information provided in the Water Point Mapping (WPM) showed that the existence of O\&M expenditure can be taken as the better indicator related to the functionality of water point.

Different sustainability rates were found for each category of water points in neighbouring districts. Further research and new questions in the WPM are needed to understand the reasons, to be able to promote the right type of water point for each place.

\section{ACKNOWLEDGEMENTS}

The authors would like to extend thanks to WaterAid Tanzania, for the data provided. R. Giné's comments and valuable collaboration are also gratefully recognised. Research grants provided by the UPC-CCD 2009 and the ACCD U2008 are also acknowledged. 


\section{REFERENCES}

Biswas, A. K. \& Seetharam, K. E. 2008 Achieving Water Security for Asia. International Journal of Water Resources Development 24 (1), 145-176.

Cleaver, F. \& Toner, A. 2006 The evolution of community water governance in Uchira, Tanzania: The implications for equality of access, sustainability and effectiveness. Natural Resources Forum 30, 207-218.

Giné, R. \& Pérez-Foguet, A. 2008 Sustainability assessment of national rural water supply program in Tanzania. Natural Resources Forum $32,327-342$.

Government of United Republic of Tanzania 1991 National Water Policy. Ministry of Water.

Government of United Republic of Tanzania 2002 National Water Policy. Ministry of Water, pp. 30.

Government of United Republic of Tanzania 2006 Water Sector Development Program. Implementation Manual, Annex 4: Formula Based allocation of financial resources to local government authorities. Ministry of Water and Irrigation.

Government of United Republic of Tanzania 2008 Water Sector Performance Report for the year 2007/2008. Ministry of Water and Irrigation, pp. 81.

Harvey, P. 2007 Cost determination and sustainable financing for rural water services in sub-Saharan Africa. Water Policy 9, 373-391.

Harve, P. \& Reed, O. 2004 Rural water supply in Africa: building blocks for handpump sustainability. WEDC, Loughborough University, UK, pp. 5-6.

Jiménez, A. \& Pérez-Foguet, A. 2008 Improving water access indicators in developing countries: a proposal using water point mapping methodology. Water Science \& Technology: Water Supply 8 (3), 279-287.
Jiménez, A. \& Pérez-Foguet, A. zoroa Building the role of local government authorities towards the achievement of the right to water in rural Tanzania. Natural Resources Forum 34 (2), 93-105.

Jiménez, A. \& Pérez-Foguet, A. zorob Challenges for water governance in rural water supply: lessons learnt from Tanzania. International Journal of Water Resources Development 26 (2), 235-48.

Rural Water Supply and Sanitation Network 2009 http://www. rwsn.ch/prarticle.2005-10-25.9856177177/prarticle.2005-1026.9228452953 (accessed 12 April 2010).

Therkildsen, O. 1988 Watering White Elephants? Lessons from Donors Funded Planning and Implementation of Rural Water Supplies in Tanzania. Scandinavian Institute of African Studies, Uppsala.

Wateraid 2009 Addressing the Sustainability Crisis. Lessons from research on managing rural water projects, July 2009. PO Box 33759, Dar es Salaam, Tanzania.

Wateraid, ODI 2005 Learning for advocacy and good practice-WaterAid water point mapping. Prepared by Katharina Welle, Water Policy Programme, Overseas Development Institute, 111 Westminster Bridge Road, London SE1 7JD, United Kingdom.

Water and Sanitation Program 2007 Country-level Sector Information and Monitoring Systems (SIMS) for Water and Sanitation in Africa. Practitioners Workshop, Nairobi, Kenya, March 2007.

WHO/UNICEF 2000 Global Water Supply and Sanitation Assessment Report. World Health Organization Press, Geneva, Switzerland.

WHO/UNICEF Joint Monitoring Programme for Water Supply and Sanitation. World Health Organization Press, Geneva, Switzerland.

World Bank 2008 Implementation Completion and results report (IDA36230, IDA-3623A) on a credit in the amount of SDR20.8 Million (US\$26.00 Million equivalent) to the United Republic of Tanzania for a Rural Water Supply and Sanitation Project. Report No:ICR 0000730. 